\title{
Social Media in Educational Practice: Faculty Present and Future Use of Social Media in Teaching
}

\author{
Marc Esteve del Valle \\ Department of Media Studies and \\ Journalism, University of Groningen \\ M.Esteve.Del.Valle@rug.nl
}

\author{
Drew Paulin \\ School of Information, \\ University of California, Berkeley \\ drew.paulin@ischool.berkeley.edu
}

\author{
Anatoliy Gruzd \\ Ted Rogers School of Management, \\ Ryerson University \\ gruzd@ryerson.ca
}

\author{
Caroline Haythornthwaite \\ School of Information Studies, \\ Syracuse University \\ chaythor@syr.edu
}

\author{
Sarah Gilbert \\ The iSchool, \\ University of British Columbia \\ s.gilbert@ubc.ca
}

\begin{abstract}
This paper presents results from a questionnaire (n=333) designed to gain an understanding of instructor motivations and experience with social media use in educational practice. Data on overall use of social media, and instructors' use of social media in classes are applied to assess factors leading to present and future use of social media in teaching, using a framework based on the Unified Theory of Acceptance and Use of Technology (UTAUT2) model. Our findings show use in teaching is driven by factors associated with UTAUT's Performance Expectancy construct, i.e., personal engagement with social media, and Moderating Condition of age, with older participants making greater use of social media in teaching. Other constructs associated with use are Habit (experience teaching online), Social Influence (colleagues using social media), Effort Expectancy (awareness of barriers, staying informed), Facilitating Conditions (institutional technology support) and Moderating Conditions (teaching at a two-year college).
\end{abstract}

\section{Introduction}

A recent Pew Internet and American Life report described social media use in the US as 'ubiquitous among younger adults' and 'notable among older adults.' In a 2015 survey of social media use in the U.S., $90 \%$ of young adults 18-29 years of age were using social media compared to only $12 \%$ in 2005 ; and $77 \%$ of adults aged $30-49$ were using social media compared to $8 \%$ in 2005 [1]. At universities, instructors are also increasingly adopting and incorporating social media in their teaching. Moran et al. [2] found that nearly two-thirds of all teaching faculty in their survey $(n=1,920)$ had used social media in their classes; and Lupton [3] in a survey of academics' use of social media $(n=711)$ found $97 \%$ of respondents used social networking sites in their academic life. However, in spite of the growing importance of social media to academics, few studies have focused on discovering instructors' reasons for using (or not) social media in teaching. This work builds on some earlier studies that examined factors behind instructors' adoption of web 2.0 technologies for teaching (e.g., [24, 25]).

To address this research gap, we designed a questionnaire to explore factors associated with faculty adoption and use of social media in teaching. The definition of 'social media' used here is deliberately broad, defined as "any website or webbased service that includes web 2.0 characteristics and contains some aspect of user generated content" [4]. This broad definition includes a wide array of possible social media tools from document sharing to microblogging to social networking sites.

With this broad definition, the questionnaire was designed to gather as much detail as possible on university instructors' social media use both inside and outside classes, and to gain an understanding of their motivations and experience with social media use in educational practice. Our first analyses of these data $[5,23]$ focused on how social media use and usefulness in teaching accorded with theoretical educational reasons for the use of social media in learning (see below).

This paper examines further the factors leading to adoption and continued use of social media in teaching. We expected a number of factors to matterfactors that map well to constructs in the Unified Theory of Acceptance and Use of Technology (UTAUT; e.g., [6]). While our questionnaire was not originally designed to include or adapt items from UTAUT studies, the wide range of questions asked provide sufficient data to model processes using this framework. The overall research question asks:

- What factors promote or inhibit social media use in teaching? 
The factors and corresponding UTAUT constructs are:

- Prior use of social media in general (Performance Expectancy)

- Experience with teaching in general and online teaching (Habit)

- Support, modelling, or observed use by peers (Social Influence)

- Barriers perceived and/or encountered (Effort Expectancy)

- Institutional support (Facilitating Conditions)

- Individual and institutional variations such as age, gender, level of instruction, institution type (Moderating Conditions).

The following provides a brief review of studies that have explored social media use by faculty in teaching, followed by a review of studies that relied on the UTAUT model to discover and explain factors in the area of social media adoption.

\section{Literature review}

\subsection{Faculty use of social media for teaching}

The surveys noted above ([2]; [3]) show that social media is being adopted in academia for personal, professional, teaching and learning purposes. Adopters appear to come from a wide range of demographics, with a number of studies finding no difference across gender, age, other uses of social media. For example, [7] found no statistically significant relationships between the use of social media in the classroom and demographics of gender, age, seniority, or highest degree earned; and [8], in a UK study with 74 respondents, found no relationship between social media use outside class and inside. However, those with early adopter characteristics have been found to be more likely to use social media in teaching [9]; as well as those who are teaching online or hybrid courses [7].

Among the types of social media used for teaching at universities, [2] found that online videos, podcasts and blogs were the most used social media by instructors in teaching. [10] found the most common use was asking students to create blogs, and second, to listen to podcasts, and then a relatively even distribution of creating, consuming, and commenting on social networking sites. [3] found motivations and uses included engaging with others in the class, engaging with external learning communities, quickly responding to information and to people, and sharing information and personal interests. In a qualitative study, [11] found that interviewees (eight instructors) emphasized the value of using social media to build communities and collaborate. Respondents in [8] saw the potential of social media as being able to promote active participation in the learning process and information dissemination.

In our initial study using data from the questionnaire reported here [23], qualitative coding of answers to questions about social media use and usefulness for teaching were analyzed in light of three theoretical reasons that emerge from education and learning theories and suggest why instructors may seek to introduce social media into their classes in support of teaching and learning: exposing students to practice; extending the learning environment; and promoting a social, collaborative approach to learning. Results of a Principal Component Factor Analysis of the coded data identified six ways social media were used for teaching (60\% of total variance explained; variance per factor 8-13\%): (1) Facilitating Engagement through student participation and reflection; (2) Organizing for Teaching by facilitating the organization of teaching activities; (3) Reaching Outside to connect the class experience to knowledge and work outside the classroom; (4) Enhancing Student Learning by using social media as a way to enhance further evaluation of class content; (5) Building a Community of Practice by fostering communities among students; and (6) Discovery of relevant information by instructors and students. These factors also accord with a Uses and Gratifications perspective that depicts adopters as active media users choosing and shaping media use to meet their own needs. Taken together, these factors provided an understanding of these instructors' diverse purposes for their use of social media for teaching.

\subsection{UTAUT and social media adoption}

UTAUT is a technology acceptance model formulated by [6] that explains factors behind why people adopt and use various computer systems. It was formulated based on an extensive study of eight prominent technology acceptance and use models, including Diffusion of Innovation Theory [12] and Technology Acceptance Model (TAM) [13]. UTAUT describes four key constructs that influence the intention to use technology [6]:

- Performance Expectancy: "the degree to which an individual believes that using the system will help him or her to attain gains in job performance" (p. 447)

- Effort Expectancy: "the degree of ease associated with the use of the system" (p. 450) 
- Social Influence: "the degree to which an individual perceives that important others believe he or she should use the new system" (p. 451)

- Facilitating Conditions: "the degree to which an individual believes that an organizational and technical infrastructure exists to support use of the system" (p. 453)

According to the model, Performance Expectancy, Effort Expectancy and Social Influence are combined to determine Behavioral Intentions to use a technology; in turn, these Behavioral Intentions and Facilitating Conditions determine final Use Behavior. Age, gender and experience are proposed to moderate various UTAUT relationships.

[6] found the UTAUT model predicted the acceptance of an information communication technology in approximately $70 \%$ of the cases. From this, they concluded that they were "approaching the practical limits of our ability to explain individual acceptance and usage decisions in organizations" ( $p$. 471). To address this, in 2012, and after many replications of the model in different fields, [14] revised UTAUT and updated it to a "consumer use context"; thus giving place to UTAUT2. Three additional constructs were integrated into UTAUT:

- Hedonic motivation: "the fun or pleasure derived from using a technology"

- Price value: 'consumers' cognitive tradeoff between the perceived benefits of the applications and the monetary cost for using them"

- Habit: "the extent to which people tend to perform behaviors automatically because of learning" ([14], pp 161-162)

UTAUT has been applied in the area of social media adoption. In the non-profit sector, [15] used UTAUT to assess the factors behind organizations' use of social media. Their research revealed how the structure of non-profit organizations affected their use of social media, concluding that "organizations with public relations departments ... were more likely to adopt social media practices than those without public relations departments" ([15], p. 90). In the medical field, a survey of health educators [16] $(n=503$, of whom 135 were academics) found Performance Expectancy and Effort Expectancy to be the two most significant constructs to explain social media use among health educators. In the political context, [17] applied UTAUT to investigate the factors for acceptance of social media in Egypt. A survey of subscribers to the Facebook page "Kalid Saied" $(n=87)$ showed that Effort Expectancy, Social Influence and Facilitating Conditions had a significant correlation with Behavioral Intention.
In higher education, a study by [4], based on 51 semi-structured interviews of academics in the field of information science and technology, employed UTAUT to explore intention and use of social media by scholars. Results revealed a positive association between UTAUT constructs Performance Expectancy and Social Influence and academics' intention and use of social media; and a negative association between Effort Expectancy and Facilitating Conditions and academics' intention and use of social media. In another study of higher education, [18] used UTAUT2 to examine conditions influencing instructors' use of technology in the classroom. Data from an online survey of business faculty members $(n=46)$ teaching face-to-face classes at a university in southeastern United States, showed that Performance Expectancy, Effort Expectancy, Social Influence and Habit were the most important constructs in explaining instructors' use of technology. Results also showed complex effects of gender as a moderating variable: Performance Expectancy and Effort Expectancy effects on intention to use classroom IT were stronger for men, while Social Influence was stronger for women.

Last, [19] employed UTAUT2 to discover the perceived advantages and relevance of Facebook as a learning tool. Analysis of data from a questionnaire completed by business administration students at a Spanish public university $(\mathrm{N}=956)$ showed that Performance Expectancy, Effort Expectancy, Social Influence, Facilitating Conditions, Hedonic Motivation and Habit all influenced students' intention to use Facebook in relation to their studies.

These multiple studies suggest the usefulness of the UTAUT model for gaining an understanding of motivations for use of social media in teaching, and thus was taken as a framework for evaluation of data from our questionnaire.

\section{Methodology}

\subsection{Questionnaire}

The questionnaire was designed to study social media use by university-level instructors of any rank or employment status. The questionnaire was launched in March 2014. To facilitate as much participation as possible, it remained open until February 2015. Recruitment was done via a variety of means, including academic mailing lists, personal emails to known or recommended contacts, and presentations at various conferences. It consisted of 27 questions in two main parts. The first part asked participants to provide information about use of social media in any 
aspect of their teaching; and the second part asked participants to answer questions about social media use in a particular class. This was followed by demographic questions about the respondent and their institution. In total, 417 respondents began the questionnaire, but after analysis, the set was reduced to 333 respondents who provided at least 10 responses to questions or parts of questions.

Demographics on gender, age, country, and discipline (number of responses per question ranged from 165 to 230) indicate our sample was: $60 \%$ women; $50 \%$ 25-40 years of age (41\% 41-60; $9 \%$ over 60), largely from English speaking countries (45\% US; 20\%: Canada: 6\% UK; 6\% Australia), but also representing a wide range of other countries: Germany and Brazil (3\%); Switzerland (2\%); Turkey, Sweden, Spain, Romania, New Zealand, Netherlands, Israel, Ireland, Denmark (1\%). Respondents came from a number of disciplines, but primarily social science areas: journalism, media studies and communication disciplines (19\%), Information Science (9\%), Education (8\%), Computer Sciences (8\%), Sociology $(6 \%)$, and a further variety of fields, from Library and Museum studies (5\%) to History (1\%), Engineering (1\%), Design (1\%), Earth Sciences (1\%), Economics (1\%) and Cultural and Ethnic Studies (1\%).

Of those who completed the second part of the questionnaire, 100 gave demographic data, with much the same distribution as above: $59 \%$ women; $49 \%$ aged $41-60 ; 50 \%$ from US, $18 \%$ Canada, $6 \%$ Australia, 5\% UK, 10\% from continental Europe, and $11 \%$ from 10 other countries. The distribution of disciplines was the same as for the full sample.

Our aim in soliciting participants was to hear from those using social media in teaching. As will be seen below, respondents are active, early adopters of social media in general, and social media in teaching.

\subsection{Data collected}

Data collected from the questionnaire covered both the types of social media respondents used in general, and those they used specifically in teaching. Two primary sets of data underpin this analysis:

- Which social media platforms respondents used in general as a consumer, i.e., read, watch, listen, visit, and as a contributor, i.e., post, share, comment, build (Table 1);

- Which social media platforms participants used in teaching: in the past, the present, and as expected use in the future (Table 2).

To avoid missing social media included in the learning management system and/or developed inhouse, general categories of social media were asked about rather than named popular tools, e.g., the questionnaire asked about use of social networking sites instead of asking about use of Facebook, LinkedIn or other sites. As noted in our definition of social media, a wide variety of social media categories were covered as listed in Table 1.

\section{Results}

\subsection{Overall use of social media by instructors}

The participants in our study were found to be active social media users, both consuming from and contributing to a number of social media platforms (see Table 1). That they are active users is not surprising given that the call for participants went out across various social media and targeted audiences who we felt were likely be active users of social media. The range of media used is wide, going well beyond SNS, blogs, and wikis. As well, use is characterized by active engagement, with high proportion of contribution: ratios of contribution to consumption range from highs of .9 for social networking sites, document sharing, synchronous discussion, to .4 for wikis.

Table 1. Overall s ocial media use

\begin{tabular}{|l|c|c|c|}
\hline Social Media Type & Consume* & Contribute & Ratio \\
\hline $\begin{array}{l}\text { Social Networking } \\
\text { Sites (SNS) }\end{array}$ & 303 & 284 & .94 \\
\hline $\begin{array}{l}\text { Multimedia } \\
\text { repository }\end{array}$ & 284 & 157 & .55 \\
\hline Document sharing & 281 & 256 & .91 \\
\hline Wikis & 276 & 113 & .41 \\
\hline Microblogging & 257 & 222 & .86 \\
\hline $\begin{array}{l}\text { Synchronous } \\
\text { discussion }\end{array}$ & 255 & 237 & .93 \\
\hline Blogs & 253 & 165 & .65 \\
\hline Academic SNS & 250 & 183 & .73 \\
\hline $\begin{array}{l}\text { Asynchronous } \\
\text { discussion }\end{array}$ & 234 & 162 & .69 \\
\hline Presentation sharing & 203 & 124 & .61 \\
\hline $\begin{array}{l}\text { Academic } \\
\text { bookmarking }\end{array}$ & 136 & 108 & .79 \\
\hline Social bookmarking & 129 & 97 & .75 \\
\hline Virtual worlds & 76 & 47 & .62 \\
\hline *Ordered by ‘Consume' & & \\
\hline
\end{tabular}

\subsection{Past, present and future use of social media in teaching}

Respondents also appear to make comparable wide-ranging use of social media in teaching (see Table 2). Most used in teaching, across all periods, are multimedia repositories, social networking sites, discussion boards, and document sharing. 
Table 2. Past, present and expected future us e of s ocial media in te aching

\begin{tabular}{|l|c|c|c|}
\hline Social Media Type & Past & Present* & Future \\
\hline Multimedia repositories & 144 & 154 & 134 \\
\hline Social networking sites & 131 & 152 & 124 \\
\hline Discussion boards & 152 & 144 & 131 \\
\hline Document sharing & 135 & 140 & 135 \\
\hline Synchronous discussion & 122 & 120 & 124 \\
\hline Microblogging & 111 & 107 & 131 \\
\hline Student Individual blogs & 137 & 105 & 127 \\
\hline Wikis & 125 & 90 & 99 \\
\hline Central course blog & 115 & 84 & 94 \\
\hline Academic SNS & 58 & 83 & 72 \\
\hline Presentation sharing & 79 & 80 & 86 \\
\hline Social bookmarking & 61 & 45 & 60 \\
\hline Academic bookmarking & 48 & 41 & 57 \\
\hline Virtual worlds & 49 & 20 & 33 \\
\hline Other & 15 & 11 & 15 \\
\hline
\end{tabular}

* Ordered by Present use

Associations across time periods are high, suggesting past use is continued into present use, and expected future use of social media. Chi-square results are all significant across time periods: past and present use: $\chi^{2}(1)=122.6, p=.000$; past and future use: $\chi^{2}(1)=140.6, \quad \mathrm{p}=.000 ;$ present and future use: $\chi^{2}(1)=196.8, \mathrm{p}=.000$.

For some media, instructors report particularly high expectations of future use, e.g., for microblogging and presentation sharing, while lower expectations for other media, such as social networking sites. Thus, even though instructors' past, present and future use of social media are positively associated, some nuances are present and may signal general changes in practice. Such information about future use can be particularly useful for planning technical and pedagogical support for both instructors and students.

\subsection{Modelling instructor use of social media}

Since the UTAUT2 model is concerned with both the adoption of a technology and its continuous use, two dependent variables were used (Table 3). SMPRESENT, the number of social media platforms instructors currently use in their teaching, was used as the best representation of the adoption stage of media use. SM-FUTURE, the number of social media platforms instructors reported they expected to use in their teaching in the future, was used as the best representation of the behavioral intention to continue using social media in teaching.

Table 4 presents the independent variables derived from instructors' answers on the questionnaire. Demographic variables for individuals include age, gender, years of teaching, number of online courses taught, whether a Massively Open Online Course (MOOC) has been taught, and academic level of teaching. Variables describing the institution, as reported by the participant, include the type of institution. Variables addressing individual level engagement with social media include the number of platforms they contribute to and the number they use only for consumption, perceived barriers to use of social media in teaching, and how they stay informed about use of social media in teaching. Variables addressing institutional level engagement, as reported by the participant, include perceived pedagogical and technological support for use of social media in teaching, and perceived use of social media by colleagues. (More details on questions used to gather the data are available in [23])

Table 3. Dependent variables us ed in the OLS Analys es

\begin{tabular}{|c|c|c|}
\hline \multicolumn{3}{|l|}{ DEPENDENT VARIABLES* } \\
\hline Variable name & Type & Range \\
\hline $\begin{array}{l}\text { SM-PRESENT } \\
\text { Number of social media } \\
\text { platforms instructors report } \\
\text { using currently in their teaching }\end{array}$ & Scale & $\begin{array}{l}\text { Range: } \\
0 \text { to } 14 \\
\text { No missing } \\
\text { values }\end{array}$ \\
\hline $\begin{array}{l}\text { SM-FUTURE } \\
\text { Number of social media } \\
\text { platforms instructors report they } \\
\text { expect to use in their teaching in } \\
\text { the future }\end{array}$ & Scale & $\begin{array}{l}\text { Range: } \\
0 \text { to } 14 \\
\text { No missing } \\
\text { values }\end{array}$ \\
\hline
\end{tabular}

*Skewness and kurtosis levels for the dependent variables SM-PRESENT $(0.686 ;-0.313)$ and SM-FUTURE (0.554; $0.994)$ are considered acceptable as they are between -2 and +2 . Additionally, a visual examination of the Q-Q plots of both variables shows that they are normally distributed.

Table 4. Independent variables used in the OLS Analys es

\begin{tabular}{|c|c|c|}
\hline \multicolumn{3}{|c|}{$\begin{array}{l}\text { INDEPENDENT VARIABLES } \\
\text { Corresponding UTAUT2 Construct }\end{array}$} \\
\hline \multicolumn{3}{|c|}{ INSTRUCTOR-LEVEL INDEPENDENT VARIABLES } \\
\hline $\begin{array}{l}\text { AGE } \\
\text { Moderating Condition }\end{array}$ & $\begin{array}{l}\text { Scale } \\
\text { Range: } \\
25 \text { to } 79\end{array}$ & $\begin{array}{l}\text { \#of } \\
\text { Missing } \\
115\end{array}$ \\
\hline $\begin{array}{l}\text { GENDER } \\
\text { Moderating Condition }\end{array}$ & $\begin{array}{l}\text { Nominal } \\
\text { 1-Male; } \\
\text { 2- Female }\end{array}$ & 101 \\
\hline $\begin{array}{l}\text { YEARS-TAUGHT } \\
\text { Habit } \\
\text { Number of years instructor has } \\
\text { been teaching. }\end{array}$ & $\begin{array}{l}\text { Scale Range: } \\
1 \text { to } 40\end{array}$ & 107 \\
\hline $\begin{array}{l}\text { ONLINE-COURSE } \\
\text { Habit } \\
\text { The level of experience of } \\
\text { teaching online courses }\end{array}$ & $\begin{array}{l}\text { Nominal } \\
0 \text { - no experience; } \\
1 \text { - taught } 1-10 \\
\text { courses; } \\
2 \text { - taught }>10\end{array}$ & 43 \\
\hline $\begin{array}{l}\text { MOOC } \\
\text { Habit } \\
\text { Whether an instructor taught a } \\
\text { Massive Open Online Course? }\end{array}$ & $\begin{array}{l}\text { Nominal } \\
1 \text { - Yes; } \\
2 \text { - No }\end{array}$ & 5 \\
\hline $\begin{array}{l}\text { ACADEMIC-LEVEL } \\
\text { Moderating Condition } \\
\text { Students' academic level in } \\
\text { which the instructor teaches }\end{array}$ & $\begin{array}{l}\text { Ordinal } \\
1-\text { UG } \\
\text { (Undergrad) } \\
2-\mathrm{G}(\text { Graduate }) \\
\end{array}$ & 103 \\
\hline
\end{tabular}




\begin{tabular}{|c|c|c|}
\hline $\begin{array}{l}\text { SM-CONTRIBUTE } \\
\text { Performance Expectancy } \\
\text { Number of different social media } \\
\text { platforms used by the respondent } \\
\text { to post content (not just in } \\
\text { teaching) }\end{array}$ & $\begin{array}{l}\text { Scale } \\
\text { Range: } \\
0 \text { to } 13\end{array}$ & 0 \\
\hline $\begin{array}{l}\text { SM-CONSUME } \\
\text { Performance Expectancy } \\
\text { Number of different social media } \\
\text { platforms used by the respondent } \\
\text { to consume information (not just } \\
\text { in teaching) }\end{array}$ & $\begin{array}{l}\text { Scale } \\
\text { Range: } \\
0 \text { to } 13\end{array}$ & 0 \\
\hline $\begin{array}{l}\text { SM-BARRIERS } \\
\text { Effort Expectancy } \\
\text { Whether the instructor feels any } \\
\text { barriers to including social media } \\
\text { in teaching } \\
\text { Note: respondents were asked to } \\
\text { write in up to } 3 \text { barriers to use. } \\
\text { This is a count only of that data. }\end{array}$ & $\begin{array}{l}\text { Nominal } \\
-1-\text { no answer; } \\
0-\text { did not report } \\
\text { any barriers; } \\
1-\text { at least one } \\
\text { barrier }\end{array}$ & 51 \\
\hline $\begin{array}{l}\text { STAY-INFORMED } \\
\text { Social Influence } \\
\text { Whether and how the instructor } \\
\text { gains information on social } \\
\text { media use in teaching } \\
\text { Note: Category was coded } \\
\text { manually to the 'closest' contact } \\
\text { (e.g., friend if both friend and } \\
\text { media were reported) }\end{array}$ & $\begin{array}{l}\text { Nominal } \\
0 \text {-don't stay } \\
\text { informed; } \\
1 \text { - friend; } \\
2 \text { - seminar; } \\
3 \text {-impersonal } \\
\text { media }\end{array}$ & 120 \\
\hline \multicolumn{3}{|c|}{$\begin{array}{l}\text { INSTITUTION-LEVEL INDEPENDENT VARIABLES } \\
\text { (as reported by the instructor) }\end{array}$} \\
\hline $\begin{array}{l}\text { INST-TYPE } \\
\text { Moderating Condition } \\
\text { Type of institution in which the } \\
\text { instructor teaches }\end{array}$ & $\begin{array}{l}\text { Ordinal } \\
1 \text { - two year pgm } \\
\text { / community } \\
\text { college; } \\
2 \text { - four year } \\
\mathrm{pgm} / \text { primarily } \\
\mathrm{UG} \text {; } \\
3 \text { - Graduate (to } \\
\text { Master's only; } \\
4 \text { - Graduate (to } \\
\text { Master's and } \\
\text { Doctoral) } \\
\end{array}$ & 103 \\
\hline $\begin{array}{l}\text { PED-SUPPORT } \\
\text { Facilitating Conditions } \\
\text { Perception of pedagogical } \\
\text { support for use of social media in } \\
\text { teaching given by the instructor's } \\
\text { institution }\end{array}$ & $\begin{array}{l}\text { Scale } \\
1 \text { (very low) to } \\
5 \text { (very high) }\end{array}$ & 103 \\
\hline $\begin{array}{l}\text { TECH-SUPPORT } \\
\text { Facilitating Conditions } \\
\text { Perception of technical support } \\
\text { for use of social media in } \\
\text { teaching given by the instructor's } \\
\text { institution }\end{array}$ & $\begin{array}{l}\text { Scale } \\
1 \text { (very low) to } \\
5 \text { (very high) }\end{array}$ & 103 \\
\hline $\begin{array}{l}\text { SM-PEERS } \\
\text { Social Influence } \\
\text { Perception of colleagues' level } \\
\text { of social media use }\end{array}$ & $\begin{array}{l}\text { Scale } \\
1 \text { (very low) to } \\
5 \text { (very high) }\end{array}$ & 103 \\
\hline
\end{tabular}

In building our conceptual model, we relied on the UTAUT2 constructs, which we tentatively map to the following independent variables bearing in mind this is one of the first studies to apply UTAUT2 to investigate why instructors adopt and use social media in their teaching. Future work will refine and validate these constructs in the teaching and learning context.

Performance Expectancy is represented by both SM-CONTRIBUTE and SM-CONSUME, as we expect that those instructors who are already active social media users in general would also likely understand how social media might be able to help them in their teaching work.

Effort Expectancy is represented by SMBARRIERS. This is because we expect that those instructors who reported barriers to using social media in teaching might be less likely to continue using social media.

Social Influence is represented by SM-PEERS, the instructors' perception of colleagues' level of social media use, and STAY-INFORMED that indicates if and how the instructor learned about the best practices of using social media in teaching (especially when they learned these from a friend). We expect that instructors whose peers use social media and/or who stay informed on these matters via their friends are also likely to use social media in their teaching.

Facilitating Conditions is represented by two variables about institutional support for the use of social media: PED-SUPPORT for pedagogical support and TECH-SUPPORT for technical support. Here we expect a higher level of institutional support will have a positive effect on one's decision to adopt and/or continue using social media for teaching.

Habit was as the level of experience of teaching, including the following variables here: YEARSTAUGHT (the number of years of teaching), ONLINE-COURSE (the level of experience of teaching online courses), MOOC (whether the instructor taught a Massive Open Online Course). We expect all three variables would positively influence the instructor's decision to use social media, especially if the instructor has some experience teaching in the online environment.

The remaining independent variables were grouped under Moderating Conditions, including individual instructor characteristics such as AGE and GENDER, and variables related to their home institution such as ACADEMIC-LEVEL (whether they teach undergraduate or graduate students) and INST-TYPE, the type of institutions (community college, undergraduate, Master's only, Master's and Doctoral).

When conducting the mapping process, we also noticed that some UTAUT2 constructs did not align themselves well within the context of the current research; namely, Price Value (since the majority of social media platforms are free to use) and Hedonic Motivation (since the intended use of the technology 
is more professional than personal); and therefore were excluded from the analysis.

\subsection{Factors explaining social media use in teaching}

We performed the Ordinary Least Square (OLS) regressions to analyze the responses from the 333 participants, using the Automatic Linear Analysis feature (SPSS statistics, version 23; [20]). The model building method was Forward Stepwise using the Information Criterion. The Automatic Linear Analysis procedure in SPSS automatically trims outliers by setting their values to a cutoff of three standard deviations from the mean, and it also merges categories of nominal variables that are not significantly different to maximize association with the dependent variable. Prior to running the regression analysis, we used the SPSS Multiple Imputation procedure to impute missing values. Following the literature [21-22], we set the number of imputations to 30 , since some of the variables had about $30 \%$ of values missing. Two analyses were conducted using the dependent variables of present, SM-PRESENT, and expected future, SM-FUTURE, use of social media in teaching; and the fourteen independent variables listed in Table 4.

The resulting models are shown in Table 5. The estimated models explain $34.7 \%$ of the variance of social media use in teaching by instructors for the present, and $30.7 \%$ for expected future use.

The analysis revealed that both instructors' Present and expected Future Use of social media in teaching were significantly positively associated with:

- Overall social media contribution behavior (SMCONTRIBUTE), mapped here to the UTAUT2 construct of Performance Expectancy

- Reporting a barrier related to social media use (SM-BARRIERS=1), mapped here to the construct Effort Expectancy

- $\quad$ Age of respondent (AGE), mapped to Moderating Conditions

And negatively associated with

- Not staying informed about social media use in teaching (STAY-INFORMED =0), mapped to Social Influence.

Present Use was also positively associated with:

- Having experience teaching a MOOC class, mapped to Habit

And negatively associated with

- Lack of experience of teaching online classes has a negative impact (ONLINE-COURSE = 1), mapped to Habit

- $\quad$ Not having colleagues using social media has a negative impact (SM-PEERS $=0,1$ ) mapped to Social Influence.
And, Future Use was positively associated with:

- Teaching at a two-year college (INST-TYPE = 1), mapped to Moderating Conditions;

- Consuming via more social media (SMCONSUME), mapped to Performance Expectancy

And negatively associated with

- Lack of technical support at one's institution (TECH-SUPPORT = 0), mapped to Facilitating Conditions.

Table 5. Automatic linear analys is results for dependent variables of present and expected future use of social media use in teaching

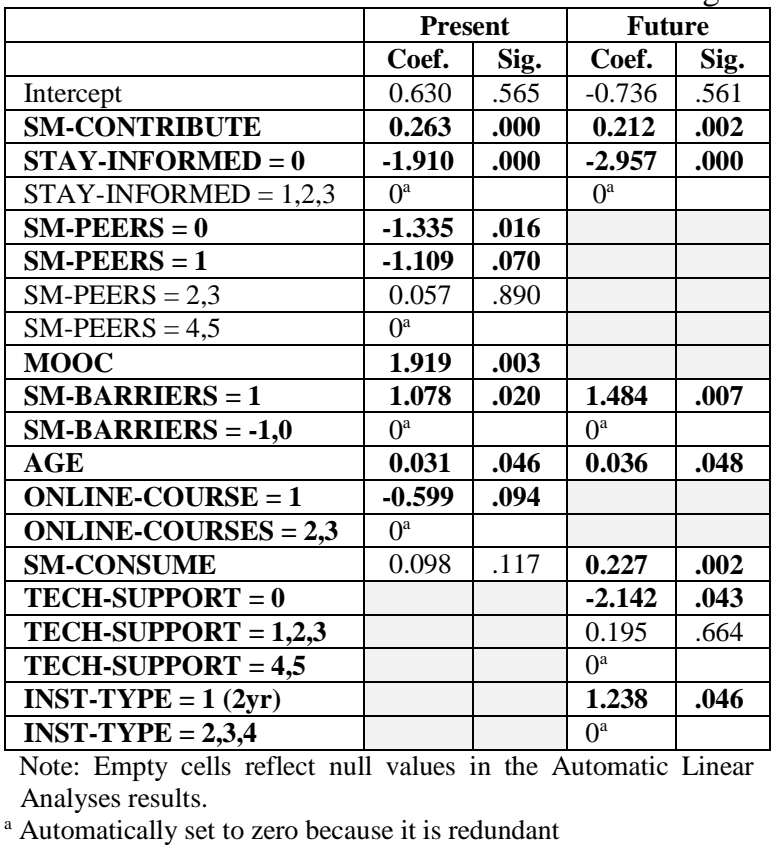

\section{Discussion}

Evaluating the results in terms of the UTAUT2 model, we found that instructors' use of social media in teaching is highly associated with their personal use of these tools: the more instructors use social media, the more they use these tools in classes. From this, we infer that use breeds a positive familiarity that promotes incorporation of these media into teaching. This accords with the Performance Expectancy construct of UTAUT2 which states that the use of technology is associated to the individual's expected gains in using the system; here modelled with variables SM-CONTRIBUTE and SM-CONSUME. But our results also offer a refinement to performance expectancy: that our results indicate show a significant role for social media consumption as a predictor of future use suggests a 2-step model of performance expectancy for incorporation into professional 
practice. Familiarity through predominantly consumption behavior supports future attention to social media in teaching, but it is both consuming and constructing that leads to actual present use in this professional context.

Results also suggest that the UTAUT2 Effort Expectancy construct has an effect on instructors' use of social media in teaching. The construct is modelled with variable SM-BARRIERS and is positively associated with social media use when an instructor reports a barrier. While at first this appears counter intuitive - that barriers associated with use support use - the variable also signals active users are aware of issues associated with use. Those who have used social media in their teaching are more likely to be aware of its challenges and constraints and thus more likely to be able to report them in the survey, and sufficiently engaged to keep trying despite these barriers. It may be that these early adopters, who operate with little institutional and peer support, are willing to take the extra effort to pioneer and perhaps also adjust their use of these systems.

The next UTAUT2 construct was Social Influence, modelled here with SM-PEERS, and STAYINFORMED, both variables that reflect how isolated or connected individuals are with others who use social media in teaching. As the theory predicted, this factor is positively associated with adoption of social media in teaching (SM-PRESENT); however, it has no effect in relation to expected continued or new social media use in the future (SM-FUTURE). Again, this may reflect the independent character of these adopters. Indeed, we might conjecture that they may be influencing others to adopt, but are not themselves influenced by others, although this is something that would need to be tested.

Also under the Social Influence construct, we expected that if an instructor staying informed about best practices of social media use via social interactions with friends or colleagues, this would positively influence the social media use. However, the results suggest that it is not necessarily how instructors staying informed, but whether they are or are not staying informed on the topic that matters those who reported 'not staying informed' on this topic were less likely to use social media in teaching than those who stayed informed in some manner. From this case it appears that any information is good information. Given this lack of social influence, it is possible that 'keeping informed' should be considered a variable associated more with Effort Expectancy than Social Influence. With that interpretation, staying informed is a behavioral characteristic associated with continued use of one's tools for teaching.
We also expected to find some association between instructors' use of social media and the technical and pedagogical support given by instructors' institutions. Our data do corroborate our initial expectations, but only in conjunction with technical support: instructors' future use of social media is negatively affected where they report a lack of technical support from their home institution. These results accord with the Facilitating Conditions construct which states that individuals' belief in organizational and technical infrastructure support is associated with the use of technology. However, we also found that this construct did not affect the extent of current use of social media in teaching. Other data from our questionnaire suggest a reason for this. In our previous study, we found overwhelmingly that current users were adopting social media not provided within the university learning management systems ([23]). Thus, lack of internal technical support is a non-issue for current use as reported by these participants, but can be seen to be a barrier to future use.

Following the Habit construct, modelled here with variables YEARS-TAUGHT, ONLINE-COURSE, MOOC, we expected instructors' use of social media to be related to their previous experience of teaching in general and/or online. Results indicated that only the online experience had a significant effect, and only on the present use of social media. This suggests that it is online habits that matter in social media use adoption for teaching. As above, since experience consuming and then contributing to social media contributes to adoption into teaching, we can expect that the media experience gained in teaching online also supports the move to include social media in teaching. For overall teaching experience, it is possible that this has been accounted by the instructor's age variable, as discussed below.

As for the fact that Habit was not significant in the Future model, one possibility is that having experience of teaching in the online setting is more important during the adoption phase (present use) than during decisions to continue using social media. Another possibility is that online teachers have reached saturation, already engaged with as many social media as they can once they are in the online environment.

Our models also highlight the effect of the Moderating Conditions, modelled here with AGE, GENDER, ACADEMIC-LEVEL, and INST-TYPE. Age but not Gender has an effect on present and future use, with greater numbers of media used in teaching by older and presumably more experienced teachers. These findings are of interest as they go against the expected trend for younger people to be more engaged with social media use. This may be interpreted to mean that to see the benefits of using social media in 
teaching, it is first necessary to understand both social media use (as demonstrated by the high number of platforms used overall) and teaching practice to know how to affect teaching using social media. This suggests another two-fold process playing into adoption of these technologies into professional practice, here the practice of teaching.

Finally, also under the Moderating Conditions, we found that those who were teaching at a two-year community college were more likely to continue or start using social media in the future. One possible explanation is that social media is broadly used by undergraduates and thus the instructor may face a higher demand to use these tools in class, and in institutions devoted to this younger age group.

\section{Conclusions and future work}

This research set out to address the overall question of what promotes or inhibits social media use in teaching, using the UTAUT framework to examine the effects of prior use, experience, support, perception of barriers, institutional support, and individual and institutional demographic variation. Our data come from a sample of active, most likely early adopters of social media use in teaching. Our respondents reported using a wide variety of social media in teaching and overall. Multimedia repositories, social networking sites, and document sharing were the most popular platforms reported for past, present, and future use for teaching. For the future, some media are expected to be used more, e.g., microblogging and presentation sharing sites, while others will be used less, e.g., social networking sites.

In exploring what promotes or inhibits social media use, we found that instructors' personal engagement with social media - the number of media contributed to, their awareness of barriers to use, their effort to keep informed about social media; - and their age - which we take to be a proxy for experience with pedagogy - are positively associated with both present and expected future use of social media in teaching. We also found that present use - our adoption condition - is further enhanced by habit, acquired through experience teaching online, and the social support of colleagues using social media in general. Future use - our behavioral intention condition - is further enhanced by two institutional factors: institutional technology support, and teaching at a two-year college.

Our findings also suggest some considerations for adoption of technology into professional practice. First, our results suggest that familiarity through social media consumption is a starting point for considering future use, but engaging through contributing is a necessary step before use in teaching, at least for these early adopters who are operating with little institutional support, and generally using technologies not supported by their institution. Second, results highlight the relation between professional practice and technology use (the socio-technical relationship). Adoption of social media into teaching appears to be favored by those with the age and experience to understand the social practices of teaching, widespread use of media to give technology fluency and choices. These ardent users also then demonstrate persistence in dealing with the inevitable sociotechnical friction, as we find that they are the ones who can report barriers, put effort to keeping informed about social media, and carry on despite the lack of institutional supports.

Overall, the UTAUT2 constructs applied here were generally useful in exploring factors behind instructors' adoption and continuing use of social media in teaching. Attention to these factors also suggested modifications of our mapping, e.g., as in the case of STAY-INFORMED, an item originally coded for social influence that turns out to be more aligned with effort. Although some constructs demonstrated a reversed relationship from the one we expected, this led to further interpretation and understanding of the data, e.g., that awareness of barriers to using social media in teaching is a positive aspect of effort, and that age and experience with teaching has a positive effect on social media use, likely due to understanding how to fit media use to pedagogical aims. Future work is needed to refine and further valid the UTAUT2 constructs by directly and more formally incorporating and testing them as part of a questionnaire.

From a more practical standpoint, our research reveals profiles of users and non-users and the factors that may influence their adoption and continuing use. For example, social media users in the teaching context are those who are older, already using social media more generally, have taught online courses, keep themselves informed about best practices in social media use, and have institutional colleagues who are also using social media. Institutions that want to encourage the future adoption and use of social media in teaching can look to more experienced instructors for pedagogical input, and to their technology offerings for further support and options for social media use.

\section{Acknowledgments}

This work is supported by a Social Sciences and Humanities Research Council of Canada (SSHRC) grant, "Learning Analytics for the Social Media Age", PIs: Anatoliy Gruzd and Caroline Haythornthwaite.

The authors would like to acknowledge and thank all of the study participants, who kindly volunteered their time and professional opinions to this study. We 
would like to thank anonymous reviewers for providing very helpful comments.

\section{References}

[1] Andrew Perrin, "Social Media Usage: 2005-2015," Pew Research Center: Internet, Science \& Tech, 08-Oct-2015.

[2] M. Moran, J. Seaman, and H. Tinti-Kane, "Teaching, Learning, and Sharing: How Today's Higher Education Faculty Use Social Media," Babson Survey Research Group, Apr. 2011.

[3] Deborah Lupton, "Feeling better connected': Academics' use of social media," News \& Media Research Centre, University of Canberra, Jun. 2014.

[4] A. Gruzd, K. Staves, and A. Wilk, "Connected scholars: Examining the role of social media in research practices of faculty using the UTAUT model," Comput. Hum. Behav., vol. 28, no. 6, pp. 2340-2350, Nov. 2012.

[5] C. Haythornthwaite, A. Gruzd, D. Paulin, S. Gilbert, and M. Esteve, "Social media use in teaching: Results from a questionnaire on use in higher education," presented at the Social Media in Higher Education conference, Sheffield, 2015.

[6] V. Venkatesh, M. Morris, G. Davis, and F. Davis, "User Acceptance of Information Technology: Toward a Unified View," Manag. Inf. Syst. Q., vol. 27, no. 3, Sep. 2003.

[7] Cheryl Du Bose, "Faculty perceptions and use of social media in the medical imaging curriculum in the United States," Dissertation, Arkansas State University, Arkansas, 2012.

[8] S. A. Brown, "Seeing Web 2.0 in context: A study of academic perceptions," Internet High. Educ., vol. 15, no. 1, pp. 50-57, Jan. 2012.

[9] A. Smith, "African Americans and Technology Use," Pew Internet Research, Jan. 2014.

[10] J. Seaman and H. Tinti-Kane, "Social Media for Teaching and Learning," Pearson Learning Solutions, Oct. 2013.

[11] B. Chen and T. Bryer, "Investigating instructional strategies for using social media in formal and informal learning," Int. Rev. Res. Open Distrib. Learn., vol. 13, no. 1, pp. 87-104, Jan. 2012.

[12] E. M. Rogers, Diffusion of Innovations, 5th Edition, 5th edition. New York: Free Press, 2003.

[13] F. D. Davis, "Perceived Usefulness, Perceived Ease of Use, and User Acceptance of Information Technology," MIS Q, vol. 13, no. 3, pp. 319-340, Sep. 1989.

[14] V. Venkatesh, J. Thong, and X. Xu, "Consumer Acceptance and Use of Information Technology: Extending the Unified Theory of Acceptance and Use of Technology," Manag. Inf. Syst. Q., vol. 36, no. 1, pp. 157-178, Mar. 2012.

[15] L. Curtis, C. Edwards, K. L. Fraser, S. Gudelsky, J. Holmquist, K. Thornton, and K. D. Sweetser, "Adoption of social media for public relations by nonprofit organizations," Public Relat. Rev., vol. 36, no. 1, pp. 9092, Mar. 2010.

[16] C. Hanson, J. West, B. Neiger, R. Thackeray, M. Barnes, and E. McIntyre, "Use and Acceptance of Social Media among Health Educators," Am. J. Health Educ., vol. 42, no. 4, pp. 197-204, Jan. 2011.

[17] B. Salim, "An Application of UTAUT Model for Acceptance of Social Media in Egypt: A Statistical Study," Int. J. Inf. Sci., vol. 2, no. 6, pp. 92-105, Dec. 2012.

[18] C. C. Lewis, C. E. Fretwell, J. Ryan, and J. B. Parham, "Faculty Use of Established and Emerging Technologies in Higher Education: A Unified Theory of Acceptance and Use of Technology Perspective," Int. J. High. Educ., vol. 2, no. 2, Mar. 2013.

[19] T. Escobar-Rodriguez, E. Carvajal-Trujillo, P. MongeLozano, "Factors that influence the perceived advantages and relevance of Facebook as a learning tool: An extension of the UTAUT," Australas. J. Educ. Technol., vol. 30, no. 2, May 2014.

[20] H. Yang, "The case for being automatic: Introducing the Automatic Linear Modeling (LINEAR) procedure in SPSS Statistics," vol. 39, no. 2, pp. 27-37, 2013.

[21] M. J. Azur, E. A. Stuart, C. Frangakis, and P. J. Leaf, "Multiple imputation by chained equations: what is it and how does it work?: Multiple imputation by chained equations," Int. J. Methods Psychiatr. Res., vol. 20, no. 1, pp. 40-49, Mar. 2011.

[22] T. E. Raghunathan, "What Do We Do with Missing Data? Some Options for Analysis of Incomplete Data," Annu. Rev. Public Health, vol. 25, pp. 99-117, 2004.

[23] A. Gruzd, C. Haythornthwaite, D. Paulin, S. Gilbert, and M. E. del Valle, "Uses and Gratifications factors for social media use in teaching: Instructors' perspectives," New Media and Society, Aug. 2016. doi: $10.1177 / 1461444816662933$

[24] H. Ajjan and R. Hartshorne, "Investigating faculty decisions to adopt Web 2.0 technologies: Theory and empirical tests," The Internet and Higher Education, vol. 11, no. 2, pp. 71-80, 2008.

[25] M. D. Roblyer, M. McDaniel, M. Webb, J. Herman, and J. V. Witty, "Findings on Facebook in higher education: A comparison of college faculty and student uses and perceptions of social networking sites," The Internet and Higher Education, vol. 13, no. 3, pp. 134-140, Jun. 2010. 